\title{
SpaCBA sequence instability and its relationship to the adhesion efficiency of Lactobacillus casei group isolates to Caco-2 cells*
}

\author{
Corinna Markowicz ${ }^{\bowtie}$, Agnieszka Olejnik-Schmidt, Monika Borkowska and Marcin T. Schmidt \\ Department of Food Biotechnology and Microbiology, Poznań University of Life Sciences, Poznań, Poland
}

The ability to adhere to enterocytes is one of the key features of probiotics. This process involves a number of factors, among which the important role of pili was demonstrated. Some Lactobacillus species are confirmed to have heterotrimeric spaCBA type pili. The aim of this study was to identify spaCBA pili in strains of selected Lactobacillus spp. and assess the impact of their presence and sequence polymorphism on the adhesion of these strains to enterocytes. Total 20 bacterial strains of $L$. rhamnosus, $L$. casei and $L$. paracasei were tested. The presence of pilus specific proteins coding genes spaA, $s p a B$ and $s p a C$ was verified by PCR in order to identify the presence of sequence polymorphism in the genes possibly affecting the structure of the spaCBA pilus. To correlate spaCBA polymorphism to adhesion capability the adhesion assay was carried out using Caco- 2 cell line. The effectiveness of the adhesion was measured using a scintillation counter. The Lactobacillus strains analyzed showed the adhesion to Caco-2 enterocytes capability from $0.6 \%$ to $19.6 \%$. The presence of spaCBA pili is a factor increasing the adhesion efficiency of Lactobacillus spp. to Caco-2 enterocytes. Lack of these structures on the surface of bacterial cells results in the reduction in adhesion efficiency, indicating its important role in the adhesion process. But not in all cases the correlation between the presence of protein spaCBA structures and adhesion efficiency was observed, what may indicate the important role of other factors in adhesion of analyzed strains to Caco-2 cells.

Key words: Lactobacillus, adhesion, spaCBA.

Received: 29 November, 2013; revised: 29 April, 2014; accepted: 19 May, 2014; available on-line: 13 June, 2014

\section{INTRODUCTION}

Adhesion importance for colonization of gut environment. Adhesion ability of bacteria is a complex phenomenon that facilitates efficient colonization of the host organism (Kimberly et al., 2009). It is a complex process based on the interactions between the surfaces of microorganism and host cells, and occurs in both pathogenic and non-pathogenic bacteria. Adhesion efficiency depends on the physical and chemical properties of the surfaces. It takes place by using a range of adhesins from a single monomeric proteins to very complex multimeric molecules. A multitude of mechanisms of adhesion makes it difficult to study. Knowledge about pathogens adhesion mechanisms is significantly larger than knowledge about non-pathogenic and probiotic bacteria adhesion (Pizarro-Cerda \& Cossart, 2006). Oc- currence of adhesion is extremely important in the gastrointestinal tract colonization by microorganisms. Adhesion to human intestinal tissue allows stable colonization by beneficial microflora and exerting its advantageous effect on human organism. It is the factor causing a number of probiotic-host interactions, including the stimulation of the host immune system (Kankainen et al., 2009). It is also one of the key criteria which allows to classify microbial strains as probiotics (Joint FAO/WHO Working Group, 2002).

Bacterial adhesins among lactobacilli. The microorganisms of the genus Lactobacillus are Gram-positive bacteria, which are a component of the intestinal microflora with a significant, positive impact on the human organism. These constitute the majority of probiotic strains used in food industry and medicine. Adhesion capacity is an important characteristic of probiotics, which determines their effectiveness. An important factor involved in the adhesion of lactobacilli to enterocytes are adhesion proteins. Adhesion proteins occurring in lactobacilli can be divided into five groups according to the type of molecules which they bind:

- Mucin binding proteins.

- Collagen binding proteins.

—Laminin binding proteins.

- Fibronectin binding proteins.

- Plasma components binding proteins.

Relatively best known are the mucus-binding proteins. They are responsible for adhesion to the mucus produced by the epithelial cells of the intestine. Their common feature is often the presence of the signal peptide and a C-terminal cell wall-anchoring LPXTG-like motif (Sanchez et al., 2008). Among these proteins two types of domains are widely used: domain MUC and domain MucBP, directly responsible for their properties (Kleerebezem et al., 2009). The first adhesive protein, with proved mucus-binding ability was the mucus-binding protein (Mub) of L. reuteri 1063 (Roos \& Jonsson, 2002). Currently, the number of known adhesive proteins capable of bonding mucus is significant. One of them is also the fimbriae $\operatorname{spaCBA}$ protein occurring in Lactobacillus rhamnosus GG (Leeber et al., 2011; Reunanen et al., 2012).

SpaCBA and its deletions. SpaCBA protein complex is an heterotrimeric pilus, which role as an adhesive protein in lactobacilli was, for the first time, confirmed in Lactobacillus rhamnosus GG (Kankainen et al., 2009). Not only the role of $\operatorname{spaCBA}$ as an adhesion molecule

更e-mail: corinnam@up.poznan.pl

*The preliminary report on the same subject was presented at MIKROBIOT 2013 Workshop, Łódź, Poland

Abbreviations: IL-8, interleukin 8; LGGISL2, Lactobacillus rhamnosus GG genomic island 2; MUC, mucin; MucBP, mucin binding protein; ORF, open reading frame; RT-PCR, reverse transcription polymerase chain reaction. 
was confirmed, but it is also known that it takes part in the formation of a biofilm and reduces the production of IL- 8 by intestinal epithelial cells, thereby reducing the immune response directed against $L$. rhamnosus GG (Lebeer et al., 2011). SpaCBA protein is composed of subunits: spaA, spaB and SpaC. spaA is the main subunit, forming the core of the pilus. SpaB subunit is located at the pilus base, and few $S p a B$ subunits can appear on the pilus fibers. $s p a C$ subunit is an mucus binding component which is located on the tip and throughout the pilus. $S p a B$ is involved in formation of $s p a C B A$ pili and has the same as subunit $\mathrm{C}$ mucus-binding capacity, although much weaker (Leeber et al., 2011; Reunanen et al., 2012). The genes encoding $\operatorname{spaCB} A$ fimbriae, as well as sortase participating in its secretion, are located in $L$. rhamnosus GG genome within LGGISL2 island (Sybesma et al., 2013). The most recent report (Sybesma et al., 2013) has shown that isolates of L. rhamnosus GG present in dietary supplements are not genetically homogeneous. Genetic changes involving the gene encoding spaCBA protein complex are deletions that lead to the inhibition of subunit $s p a C$ synthesis, and a reduced capacity to adhesion of the tested strains.

In our study we analyzed presence of $s p a C B A$ coding sequence in several strains of Lactobacillus spp. belonging to Casei group. Several strains showed weak adhesion efficiency to Caco-2 cells and deletions or sequence variation within $s p a C B A$ operon. However, there were strains that contained intact $\operatorname{spaCB} A$ coding sequence but exhibited weak adhesion efficiency. This is the first examination, to our knowledge, of $s p a C B A$ polymorphism and its correlation to adhesion property of Lactobacillus strains.

\section{MATERIALS AND METHODS}

Bacteria and human cells. Lactobacillus spp. belonging to Casei group (according to Felis, Dellaglio, 2001): human isolates from Departmental Culture Collection and strains from dietary supplements used in this study (Table 1) were grown in MRS broth (Biocorp, Poland) at $37^{\circ} \mathrm{C}$ in anaerobic conditions. Human colon adenocarcinoma cell line Caco- 2 was used in the adhesion assay (Sambuy et al., 2005). The cell line was obtained from the European Collection of Cell Cultures (ECACC) and cultured in Dulbecco's modified Eagle's minimal essential medium (Lonza, Belgium) that contained 10\% (v/v) heat-inactivated fetal calf serum (Lonza, Belgium) and $1 \%$ non-essential amino acids (Lonza, Belgium). Cells were grown at $37^{\circ} \mathrm{C}$ in an atmosphere of $10 \% \mathrm{v} / \mathrm{v} \mathrm{CO}_{2}$ in air.

Bacteria identification. Bacteria identification was performed as described by Suau and coworkers (1999), briefly: DNA from bacterial cultures were isolated with Genomic Mini Kit (A\&A Biotechnology, Poland) according to the manufacturer instruction. Primer pair S-DBact-0008-a-S-20 (5' AGA GTT TGA TCC TGG CTC AG 3') and S-Univ-1492-b-A-21 (5' ACG GCT ACC TTG TTA CGA CTT 3') was used to amplify bacterial $16 \mathrm{~S}$ rDNAs by PCR. Reaction tubes contained $50 \mathrm{ng}$ genomic DNA, 1.5 U of RUN DNA polymerase (A\&A Biotechnology, Poland), $1 \times$ reaction buffer supplemented to $2.5 \mathrm{mM} \mathrm{MgCl}_{2}, 200 \mu \mathrm{M}$ each deoxyribonucleotide triphosphate, and $0.44 \mu \mathrm{M}$ each primer in a final volume of $50 \mu$ l. Initial DNA denaturation and enzyme activation steps were performed at $94^{\circ} \mathrm{C}$ for $5 \mathrm{~min}$ in a Veriti thermocycler (Life Technologies, Poland), followed by 15 cycles of denaturation at $92^{\circ} \mathrm{C}$ for $1 \mathrm{~min}$, annealing at $48^{\circ} \mathrm{C}$ for $1 \mathrm{~min}$, and elongation at $72^{\circ} \mathrm{C}$ for $1 \mathrm{~min}$
Table 1. Bacterial strains used in the study.

\begin{tabular}{|c|c|}
\hline $\begin{array}{l}\text { Isolate } \\
\text { name }\end{array}$ & Source \\
\hline DS1 & $\begin{array}{l}\text { Lactoral probiotic supplement, Biomed-Kraków, Po- } \\
\text { land }\end{array}$ \\
\hline DS2 & Dicoflor probiotic supplement, Vitis Pharma, Poland \\
\hline DS3 & Ellen probiotic tampon, Ellen $A B$, Sweden \\
\hline DS5 & Yacult probiotic drink, Yakult Europe, The Netherlands \\
\hline DS6 & Latopic probiotic supplement, Biomed-Kraków, Poland \\
\hline DS7 & Ecovag probiotic supplement, Krotex, Poland \\
\hline DS8 & Fyos probiotic drink, Nutricia, Belgium \\
\hline DS9 & Lakcid probiotic supplement, Biomed-Lublin, Poland \\
\hline DS10 & $\begin{array}{l}\text { Lactovaginal probiotic supplement, Biomed-Kraków, } \\
\text { Poland }\end{array}$ \\
\hline DS11 & Lacibios probiotic supplement, ASA, Poland \\
\hline DS12 & Lakcid probiotic supplement, Biomed-Lublin, Poland \\
\hline DS13 & Lakcid probiotic supplement, Biomed-Lublin, Poland \\
\hline DS14 & Latopic probiotic supplement, Biomed-Kraków, Poland \\
\hline HI1 & Human stool isolate \\
\hline $\mathrm{H} 2$ & Human stool isolate \\
\hline $\mathrm{HI3}$ & Human stool isolate \\
\hline $\mathrm{H} 14$ & Human stool isolate \\
\hline HI5 & Human stool isolate \\
\hline H16 & Human stool isolate \\
\hline HI7 & Human stool isolate \\
\hline
\end{tabular}

$30 \mathrm{~s}$, which was followed by a final elongation at $72^{\circ} \mathrm{C}$ for $15 \mathrm{~min}$. PCR products were purified and concentrated with Clean-Up kit (A\&A Biotechnology, Poland). Purified amplicons were send for sequencing to Genomed S.A. (Warsaw, Poland), each amplicon was sequenced from both strands in extra-long run service. Obtained sequences of both strands were aligned and combined, and then compared to those available in public databases (Ribosomal Database Project and GenBank) in order to ascertain their closest relatives. This allows to confirm taxonomy at genus level and indicates the closest match at species level.

Adhesion assay. Adhesion assay was performed as described previously by Schmidt and coworkers (2010), briefly: to label bacteria methyl- $\left[{ }^{3} \mathrm{H}\right]$-thymidine (60-90 $\mathrm{Ci} / \mathrm{mmol}, 1 \mathrm{mCi} / \mathrm{ml}$; Hartmann Analytic GmbH, Germany) was added to the medium at a volume of $5 \mu \mathrm{l} / \mathrm{ml}$ of broth. After 18-20 hours of growth, the bacteria were washed twice with sterile Hank's Buffered Salts Solution (HBSS) and resuspended in the same buffer. Monolayers of Caco-2 cells were prepared in PTFE filter $(0.3 \mu \mathrm{m}$ pore size) inserts for 6 -well tissue-culture dishes (Merck-Millipore, Poland) by inoculating $2 \times 10^{6}$ viable cells (passage no. 49-52) per insert in $2.0 \mathrm{ml}$ culture medium. The cells were cultivated for three weeks to allow differentiation. Medium was replaced every 2 days. Twenty one-days-post-confluent Caco-2 cell monolayers were washed once with $1 \mathrm{ml}$ sterile HBSS before the adhesion assay. Bacteria at concentrations of approximately $5 \times 10^{8}$ $\mathrm{cfu} / \mathrm{ml}$ were added to each well in $2.0 \mathrm{ml}$ (total volume) HBSS and incubated at $37^{\circ} \mathrm{C}$ in an atmosphere of $10 \%$ $(\mathrm{v} / \mathrm{v}) \mathrm{CO}_{2}$ in air. After $60 \mathrm{~min}$ incubation, monolayers were washed three times with sterile HBSS to remove 
Table 2. Primers used for PCR reactions.

\begin{tabular}{|c|c|c|c|}
\hline Target (use) & Name & Sequence $\left(5^{\prime}-3^{\prime}\right)$ & Product length $(b p)$ \\
\hline \multirow{4}{*}{ spaA (detection) } & spaA1f & TCGATTGACGTGGGTTGCTGAAAGCGATGCTACTG & \multirow{2}{*}{229} \\
\hline & spaA1r & TGCGGCGCTTGCGATAGGCAACTGCTCCAAATGC & \\
\hline & spaA2f & GGCGATGGTGCTAAGCCTTTACAAGGCGTTG & \multirow{2}{*}{304} \\
\hline & spaA2r & CATAGACATTCCCGTCGGCTGCTGCCTTGGCTGG & \\
\hline \multirow{4}{*}{ spaB (detection) } & spaB1f & TGGCAACGACAACGTTGCAGCAGACACAGGCGG & \multirow{2}{*}{323} \\
\hline & spaB1r & CGCTTCTCCCTGACCAGCCGTCACAACCTGTGCG & \\
\hline & spaB2f & TCGCACAGGTTGTGACGGCTGGTCAGGGAGAAGCG & \multirow{2}{*}{295} \\
\hline & spaB2r & AGCCAAGCTGCAACTGTATCACCCGTTTGTGGC & \\
\hline \multirow{4}{*}{ spaC (detection) } & spaC1f & CGCTCAACGTCACGGTGCAGCGAAAAGTGGCTG & \multirow{2}{*}{408} \\
\hline & spaC1r & GCGCTAGTGCCTGCAGATCCGTTGACGTGATGGCG & \\
\hline & $\mathrm{spaC2f}$ & AGGTGCAGCGTTCACCCTGCAACCAAGTGCTGGCG & \multirow{2}{*}{366} \\
\hline & spaC2r & CCCAGTGCGATACCAAGCAATCGCTGATAGCCCTG & \\
\hline \multirow{2}{*}{ spaA (ORF amplification) } & SpaAvf & CTTGCTTGACTCATTTATCTTATTAACTTT & \multirow{2}{*}{1065} \\
\hline & SpaAvr & CCAAAAAATTAATAAGTGGGAGAGA & \\
\hline \multirow{2}{*}{ spaB (ORF amplification) } & SpaBvf & GCACTTTCTTGGCAATTGTCT & \multirow{2}{*}{785} \\
\hline & SpaBvr & TITGATAAAGCGACGGGTG & \\
\hline \multirow{2}{*}{ spaC (ORF amplification) } & SpaCvf & AAGGTCAAAATCACTAACGGACG & \multirow{2}{*}{2747} \\
\hline & SpaCvr & TTA CTGAGAGGAGGGTAAAATTAACG & \\
\hline \multirow{2}{*}{ spaCBA (ORFs amplification) } & SpaAvf & CTTGCTTGACTCATTTATCTTATTAACTTT & \multirow{2}{*}{4472} \\
\hline & SpaCvr & TTA CTGAGAGGAGGGTAAAATTACG & \\
\hline
\end{tabular}

free bacterial cells. Amount of adhered bacterial cells was estimated from radioactivity remaining at Caco-2 monolayer. Each assay was performed in triplicate. Radiolabeled bacteria in amount initially added for adhesion and washed Caco- 2 monolayer with adhered radiolabeled bacteria were lysed in $0.9 \mathrm{ml}$ of $1 \%$ SDS, then $0.1 \mathrm{ml}$ of $1 \mathrm{M} \mathrm{NaOH}$ was added and the lysate was incubated overnight at $60^{\circ} \mathrm{C}$ to complete lysis. The radioactivity of the lysed suspension was measured by liquid scintillation in Beckmann LS6500 after addition of Hionic-Fluor scintillation cocktail (Perkin-Elmer, Poland).

Primer design. Primers for $s p a A$, spaB, and $s p a C$ sequence detection were designed with PriFi service (Fredslund et al., 2005) based on DNA sequence alignments. Sequences of $\operatorname{spaCB} A$ operon available from GenBank database identified with BLAST search (accession nos.: AP011548.1, FM179322.1, HE970764.1, CP002618.1, CP002616.1, FM177140.1, CP000423.1, CP001084.1) were aligned and submitted to PriFi service to design primer pairs targeting conservative sequence regions to avoid false negative results. Two primer pairs were selected for each ORF (spaC, spaB, and spaA) to amplify sequence fragments at their 5'- and 3'-proximal regions (Table 2).

RFLP. For sequence polymorphism analysis of $s p a A$, $s p a B$ and $s p a C$ ORFs primer pairs were designed flanking the sequences of interest (Table 2). Reaction tubes contained $50 \mathrm{ng}$ genomic DNA, 1 U of Phusion Hot Start
II High-Fidelity DNA Polymerase (Thermo Scientific), $1 \times$ reaction buffer, $200 \mu \mathrm{M}$ each deoxyribonucleotide triphosphate, and $0.50 \mu \mathrm{M}$ each primer in a final volume of $50 \mu \mathrm{l}$. Initial DNA denaturation was performed at $98^{\circ} \mathrm{C}$ for $30 \mathrm{~s}$ in a Veriti thermocycler (Life Technologies, Poland), followed by 32 cycles of denaturation at $98^{\circ} \mathrm{C}$ for $10 \mathrm{~s}$, annealing at $56^{\circ} \mathrm{C}$ for $30 \mathrm{~s}$, and elongation at $72^{\circ} \mathrm{C}$ for $30 \mathrm{~s}$, which was followed by a final elongation at $72^{\circ} \mathrm{C}$ for $5 \mathrm{~min}$. PCR products were purified and concentrated with Low Elution cDNA Purification Module (Invitrogen), and then digested with restriction enzymes Fnu4HI (Sat I) (Thermo Scientific) and ScrFI (Bme1390I) (Thermo Scientific) for $4 \mathrm{~h}$ at $37^{\circ} \mathrm{C}$. The restriction fragments length patterns were analyzed using Agilent 2100 Bioanalyzer (Agilent) with Agilent DNA $7500 \mathrm{Kit}$ (sizing resolution $\pm 5 \%$ for $100-1000 \mathrm{bp}$ and $\pm 15 \%$ for $1000-7500 \mathrm{bp}$ ).

RNA isolation and RT-PCR. Total RNA from bacterial cultures were isolated with TRI Reagent (Sigma-Aldrich) according to manufacturer instruction with cells disruption facilitated by beads-beating with $2 \mu \mathrm{m}$ glass beads in Mixer Mill MM400 (Retsch) at $50 \mathrm{~Hz}$ for 6 min. Obtained RNA was further purified with TURBO DNA-free Kit (Life Technologies) to remove genomic DNA contamination. The purified RNA was used in PCR reaction to exclude the presence of residual DNA in samples. For this purpose, primers spaA1, spaA2, spaB1 and spaB2 were used for PCR reaction prepared 
Table 3. Adhesion efficiency of tested lactobacilli isolates and their taxonomic identity.

\begin{tabular}{|c|c|c|}
\hline Isolate & $\begin{array}{l}\text { Closest match at the species } \\
\text { level }\end{array}$ & $\begin{array}{l}\text { Adhesion efficiency } \\
(\%)\end{array}$ \\
\hline HI1 & L. paracasei & 20 \\
\hline DS1 & L. rhamnosus & 15 \\
\hline $\mathrm{HI} 2$ & L. casei & 7 \\
\hline $\mathrm{HI} 3$ & L. casei & 7 \\
\hline $\mathrm{HI} 4$ & L. rhamnosus & 6 \\
\hline DS2 & L. rhamnosus & 5 \\
\hline HI5 & L. rhamnosus & 5 \\
\hline HI6 & L. casei & 4 \\
\hline HI7 & L. casei & 4 \\
\hline DS3 & L. rhamnosus & 3 \\
\hline DS5 & L. casei & 2 \\
\hline DS6 & L. paracasei & 2 \\
\hline DS7 & L. rhamnosus & 2 \\
\hline DS8 & L. casei & 2 \\
\hline DS9 & L. rhamnosus & 2 \\
\hline DS10 & L. rhamnosus & 2 \\
\hline DS11 & L. rhamnosus & 2 \\
\hline DS12 & L. rhamnosus & 1 \\
\hline DS13 & L. rhamnosus & 1 \\
\hline DS14 & L. rhamnosus & 1 \\
\hline
\end{tabular}

as described above. Genomic DNA-free RNA was reverse transcribed into cDNA using High Capacity RNAto-cDNA Kit (Life Technologies). Obtained cDNA was used in PCR for detection of $s p a A, s p a B$ and $s p a C$ sequences as described above.

\section{RESULTS}

Adhesion. The main role of $\operatorname{spa} C B A$ fimbriae is the adhesion to mucosal surface of the gastrointestinal tract. Therefore, we decided to collect a group of Lactobacillus strains belonging to Casei group with various adhesion efficiency. Tested isolates showed large adhesion efficiency variation that ranged from $1 \%$ to $20 \%$. The most adhesive isolate was L. paracasei, a human stool isolate (HI1). The least adhesive isolate was Lactobacillus rhamnosus designated DS13, derived from dietary supplement (Table 3).

$\operatorname{SpaCB} A$ sequence detection. The next task was to confirm presence of $\operatorname{spaCB} A$ coding sequences in the tested strains' genomes. To reach that goal PCR assay was developed with primer pairs targeting the conserved sequence regions at 5'- and 3'-proximity of each open reading frame. Out of the 20 isolates analyzed, 19 were tested positive for spaA sequence. The detection result was assumed positive where at least one of the two pairs of primers gave amplification product of expected molecular weight. Among these 19 spaA-positive isolates a group of 16 were tested positive for $s p a B$ ORF. Further analysis revealed that out of these $16 \mathrm{spaBA}$-positive strains 11 were shown to contain $\mathrm{SpaC}$ coding sequence. However, DS9 isolate characterized by spaB-negative amplification was tested positive for $s p a C$. PCR directed to amplify the entire sequence of $s p a C B A$ gave positive results for 13 isolates. However, amplification of each ORF separately resulted in successful amplification for $s p a A$ in 11 isolates, for $s p a B$ in 14 isolates and for $s p a C$ only 2 isolates. The results of each PCR reaction is shown in Table 4.

Variation among $\operatorname{spaCBA}$. Differences between spaCBA sequence detected in the tested strains are likely to be significant. Differences between a sequence of the studied isolates mainly concern $\mathrm{C}$ subunit-coding sequence of $s p a C B A$ protein. Differences in a sequence of the analyzed fragments detected by restriction fragment length polymorphism occurred in all types of PCR products corresponding to protein $\operatorname{spaCB} A$ subunits $\mathrm{C}$, $\mathrm{B}$ and $\mathrm{A}$ (Table 5). The restriction patterns (in case of all subunits) closest to the expected pattern as this of the reference strain (L. rhamnosus GG) occurred in isolate DS2 (L. rhamnosus). The second most similar to it was the isolate DS1 (L. rhamnosus). Isolate HI3 (L. casei) revealed the most different RFLP pattern in terms of each subunit of $s p a C B A$ protein complex. Restriction patterns of A subunit was the most stable. In the case of subunit $\mathrm{B}$, the main difference between LGG strain and the other was based on lack of a restriction site in about two thirds length of the subunit sequence. Six strains showed an additional restriction site in the 5'-proximal sequence region (HI2, HI1, DS2, HI5, HI6, DS6). In the case of subunit $\mathrm{C}$, two isolates (giving expected C-subunit PCR product length) had a very similar restriction pattern. There were also performed restriction digestion of PCR products of two strains which did not yield the expected product length, but much shorter (isolate HI2, $1437 \mathrm{bp}$ ) or much longer (isolate DS6, $3450 \mathrm{bp}$ ) products. In both cases, a restriction fragment pattern is partially similar to reference pattern (LGG strain). However, there were a number of additional restriction sites or loss of some restriction sites.

RT-PCR. To verify expression of $s p a C B A$ operon to mRNA level 10 isolates confirmed for presence of the entire operon sequence were tested. Total RNA purified from HI1, HI2, HI3, HI5, HI6, DS1, DS2, DS5, DS6, and DS8 isolates were confirmed to be genomic DNAfree by PCR, then reverse transcribed with random hexamer primer. The RT-PCR analysis based on detection of spaA and $s p a B$ sequences confirmed expression of spaCB $A$ operon in DS1, DS2, HI1, HI2, HI3 and HI6 isolates (not shown).

\section{DISCUSSION}

Coding sequence amplification and sequence polymorphism. Successful PCR amplification depends on successful hybridization of primers to template, especially regarding 3 '-ends of primers. The lack of amplification product may indicate no template (deletion event) or inability of primers to hybridize to template due to sequence polymorphism. To avoid the latter possibility a 
Table 4. Detection and amplification of $s p a A$, spaB, spaC and spaCBA sequences.

Positive sign (+) denotes presence of amplicon of expected molecular weight (specific amplification), negative sign (-) denotes lack of amplification, amplicons of other than expected molecular weight were recognized as non-specific (ns). In several cases coexistence of specific and non-specific amplification was observed.

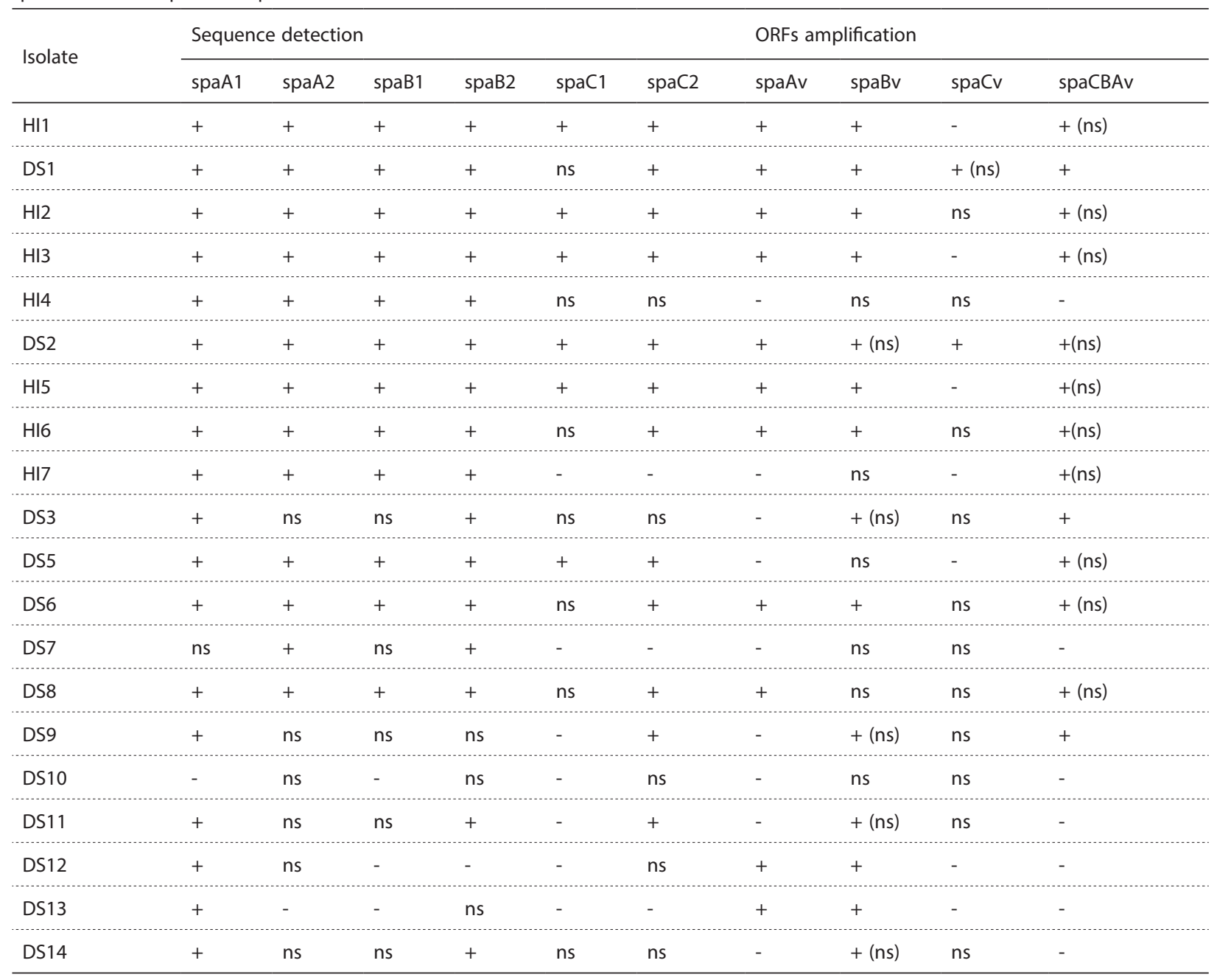

specific approach was developed. $\operatorname{spa} C B A$ sequence of $L$. rhamnosus GG available in GenBank database was used as a query in BLAST search to identify homologous sequences of other Lactobacillus taxonomically closely related species and strains. Selected sequences from the search results returned were aligned to identify polymorphic sequence sites and primer pairs were designed that target conserved sequence motifs. To ascertain detection process two primer pairs were selected for each open reading frame. Another assay confirming presence of the sequence was PCR for amplification of entire sequence of each ORF separately with primers designed on the $s p a C B A$ sequence of the reference strain ( $L$. rhamnosus GG; GenBank accession nr AP011548.1). A group of five isolates (HI1, DS1, HI2, HI3, and HI5) were tested positive by all PCR assays. In either case one of 3 tests for $s p a C$ sequences failed to amplify its target. Two isolates (DS3 and HI7) were unsuccessful in all three spaC amplification assays but produced amplicons of expected molecular weight in full operon amplification assay $(\operatorname{spaCB} A)$. Together with the finding that the assays for $s p a C$ amplification were the most unproductive in case of tested isolates it can be assumed that $s_{p a C}$ sequence is the most polymorphic.
Expression of $s p a C B A$ subunits. Analysis of $s p a C$ $B A$ operon expression was carried out using RT-PCR. The analysis was performed for 10 strains which gave a positive detection result for $s p a C,-\mathrm{B}$ and $-\mathrm{A} O \mathrm{ORFs}$, and amplification of the entire $\operatorname{spa} C B A$ coding sequence. Reverse transcription-PCR reaction gave positive results with primers detecting spaA and spaB ORFs in case of DS1, DS2, HI1, HI2, HI3, and HI6 isolates. Despite the negative RT-PCR reaction for $s p a C$ it can be assumed that the operon was expressed since $s p a C B A \mathrm{mRNA}$ is polycistronic and $s p a C$ is at the 5'-end of the transcript (Toh et al, 2013). A negative RT-PCR for spaC sequence might be due to complex secondary structure of the RNA resulting in low efficiency of reverse transcription that was carried at $37^{\circ} \mathrm{C}$. For unambiguous determination of $\operatorname{spaCBA}$ expression specific antibodies need to be generated to confirm the protein presence by blot analysis. However, RT-PCR analysis confirmed $s p a C B A$ expression in tested isolates that showed adhesion level at $4 \%$ and higher (except of HI5). Therefore, despite sequence variation within $\operatorname{spaCB} A$ coding sequence a transcription level differences may contribute to adhesion differencies of the isolates. 
Table 5. Length of amplicons obtained in PCR amplification of whole ORFs (spaAv, spaBv, spaCv) and DNA fragments obtained after their restriction digestion with Satl or ScrFI for selected isolates (HI1, DS1, HI2, HI3, DS2, HI5, HI6, DS8, DS6).

LGG designate theoretical data based on sequence of $L$. rhamnosus GG spaCBA form GenBank (accession nr AP011548.1).

\begin{tabular}{|c|c|c|c|c|c|c|c|c|c|c|}
\hline \multirow{2}{*}{$\begin{array}{l}\text { Length of fragments } \\
\text { (bp) }\end{array}$} & \multicolumn{10}{|c|}{ Isolate } \\
\hline & LGG & $\mathrm{HI} 1$ & DS1 & $\mathrm{HI} 2$ & $\mathrm{HI} 3$ & DS2 & HI5 & HI6 & DS6 & DS8 \\
\hline spaAv after Satl & $\begin{array}{l}90 \\
90 \\
164 \\
351 \\
370\end{array}$ & $\begin{array}{l}84 \\
84 \\
157 \\
342 \\
361\end{array}$ & $\begin{array}{l}84 \\
84 \\
157 \\
343 \\
358\end{array}$ & $\begin{array}{l}80 \\
80 \\
153 \\
339 \\
360\end{array}$ & $\begin{array}{l}84 \\
84 \\
129 \\
158 \\
265 \\
271\end{array}$ & $\begin{array}{l}83 \\
83 \\
156 \\
342 \\
356\end{array}$ & $\begin{array}{l}82 \\
82 \\
155 \\
341 \\
360\end{array}$ & $\begin{array}{l}84 \\
84 \\
158 \\
342 \\
361\end{array}$ & $\begin{array}{l}83 \\
83 \\
155 \\
341 \\
354\end{array}$ & $\begin{array}{l}83 \\
83 \\
156 \\
341 \\
357\end{array}$ \\
\hline spaAv & 1065 & 1028 & 1018 & 1012 & 991 & 1020 & 993 & 1029 & 1016 & 1020 \\
\hline spaBv asfer Satl & $\begin{array}{l}50 \\
55 \\
70 \\
130 \\
132 \\
155 \\
193\end{array}$ & $\begin{array}{l}112 \\
118 \\
118 \\
170 \\
180\end{array}$ & $\begin{array}{l}110 \\
118 \\
118 \\
171 \\
183\end{array}$ & $\begin{array}{l}107 \\
117 \\
117 \\
169 \\
180\end{array}$ & $\begin{array}{l}80 \\
120 \\
120 \\
173 \\
188\end{array}$ & $\begin{array}{l}117 \\
117 \\
154 \\
171 \\
182\end{array}$ & $\begin{array}{l}107 \\
117 \\
117 \\
170 \\
180\end{array}$ & $\begin{array}{l}110 \\
117 \\
117 \\
172 \\
186\end{array}$ & $\begin{array}{l}109 \\
119 \\
119 \\
171 \\
184\end{array}$ & \\
\hline spaBv & 785 & 698 & 697 & 690 & 681 & 741 & 691 & 702 & 702 & - \\
\hline $\begin{array}{l}\text { SpaC after } \\
\text { ScrFI }\end{array}$ & $\begin{array}{l}210 \\
235 \\
240 \\
294 \\
332 \\
363 \\
340 \\
733\end{array}$ & & $\begin{array}{l}198 \\
225 \\
239 \\
292 \\
330 \\
357 \\
376 \\
703\end{array}$ & $\begin{array}{l}200 \\
241 \\
332 \\
663\end{array}$ & & $\begin{array}{l}200 \\
224 \\
239 \\
292 \\
333 \\
362 \\
381 \\
710\end{array}$ & & & $\begin{array}{l}200 \\
227 \\
241 \\
289 \\
332 \\
380 \\
659 \\
710\end{array}$ & \\
\hline SpaC & 2747 & - & 2720 & 1436 & - & 2741 & - & - & 3038 & - \\
\hline
\end{tabular}

SpaCBA vs adhesion. Seven of ten isolates tested positive for coding sequences of all subunits of $s p a C$ $B A$ protein complex and the entire $\operatorname{spaCB} A$ sequence, showed adhesion efficiency to Caco-2 cells of above $3 \%$. Adhesion efficiency of the other three isolates was ap-

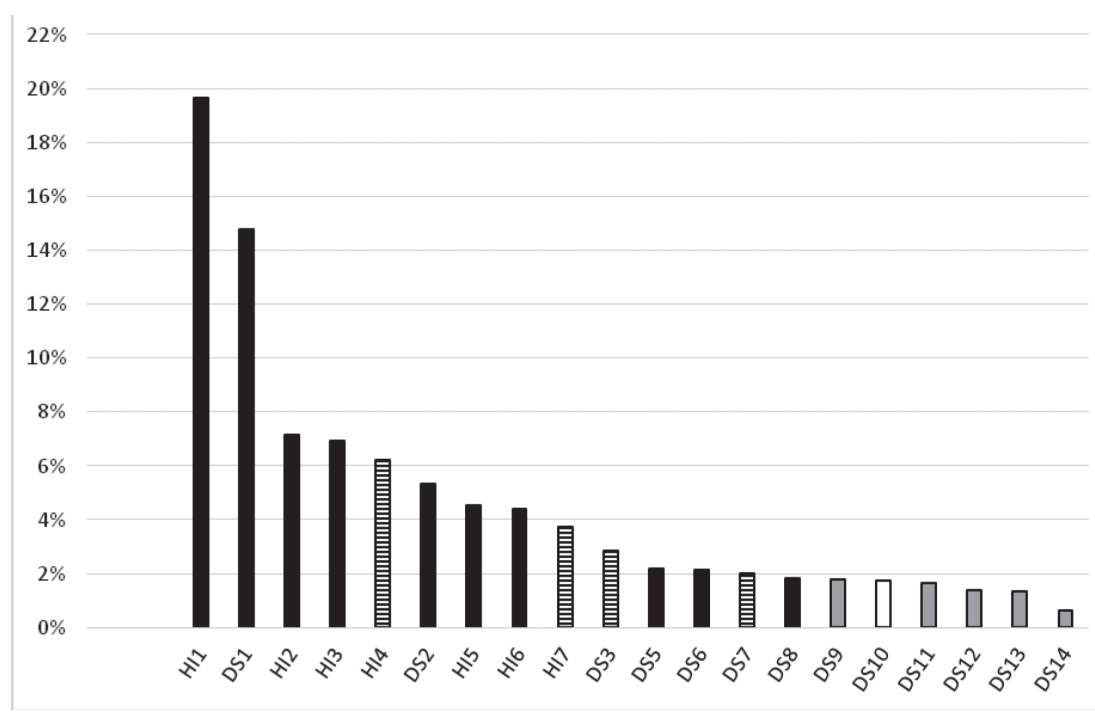

Figure 1. Juxtaposition of adhesion efficiency of tested isolates to differentiated Caco-2 monolayer and results of spaCBA sequence detection by PCR.

Black bars indicate isolates producing positive PCR result for detection of subunit $A, B, C$ coding sequences and positive result of whole spaCBA sequence amplification. The other strains gave negative result of whole spaCBA sequence amplification, but positive results for detection of two (striped bars) or one (grey bars) of spaCBA ORFs. White bar denote negative amplification results for all reactions. proximately $2 \%$. The most efficient amplification of pronounced PCR products were obtained for four strains with the highest adhesion efficiency (strain HI1, DS1, $\mathrm{HI} 2$ and HI3). Isolates with adhesion efficiency below $1,8 \%$ were positive for $\operatorname{spaCBA}$ PCR maximally for two subunits (although the amplification reaction had low efficiency), strain DS11 and DS14 - for A and B subunit, strain DS9 - for $A$ and $C$ subunit, DS12 and DS13 - only for A subunit, DS10 - for none subunit. Among the strains with the lowest adhesion efficiency, the presence or absence of a positive PCR result for the sequences detection did not clearly correlated with adhesion efficiency (Fig. 1).

Out of ten isolates tested for spaCBA transcription, in which coding sequences of subunits $\mathrm{C}, \mathrm{B}$ and $\mathrm{A}$ were detected, six showed the presence of $s p a C B A$ transcript. These strains are characterized by a high level of adhesion to differentiated Caco- 2 cell monolayer (from $4 \%$ to $20 \%$ ). There were also two strains of outstanding adhesion efficiency $(20 \%$ and $14 \%)$ among all tested isolates. The DS5, DS6, and DS8 isolates that were tested positive for entire $s p a C B A$ coding sequence were negative for the operon transcription, what may 
explain their low adhesion efficiency. Other isolates were shown to lack one or more $s p a C B A$ ORFs or presence of the sequence variation, that may explain their low adhesion properties. Three isolates (HI4, HI7, and DS3) do not fit the above explanation indicating possible presence of another adhesion factor suggesting that $s p a C B A$ is major but not exclusive adhesion for Lactobacillus Casei group.

\section{Acknowledgments}

This work was supported by the Polish National Science Centre grant no. N N312 272640 in years 20112014.

\section{Authors' Contributions}

CM contributed to the adhesion assay, RFLP and SSCP analysis, data collection and interpretation, drafting and writing of the manuscript. AOS contributed to the bacteria identification and drafting of the manuscript. MB contributed to culture of the animal cells. MS contributed to conception of the idea, primer design, data collection and interpretation, and writing of the manuscript. All read and approved the manuscript.

\section{REFERENCES}

Felis GE, Dellaglio F (2007) Taxonomy of lactobacilli and bifidobacteria. Curr Issues Intestinal Microbiol 8: 44-61.

Fredslund J, Schauser L, Madsen LH, Sandal N, Stougaard J (2005) PriFi: using a multiple alignment of related sequences to find primers for amplification of homologs. Nucleic Acids Res 33 (Web Server issue): W516-W520.

Joint FAO/WHO Working Group on Drafting Guidelines for the Evaluation of Probiotics in Food. Guidelines for the evaluation of probiotics in food: report of a Joint FAO/WHO.

Kankainen M, Paulina L, Tynkkynenb S, Von Ossowskic I, Reunanenc J, Partanena P, Satokarid R, Vesterlundd S, Hendrickxe APA, Lebeerf S, De Keersmaeckerf SCJ, Vanderleydenf J, Hamalainena T, Laukkanena S, Salovuoria N, Ritaria J, Alataloa E, Korpelabg R, Mattila-Sandholmb T, Lassigh A, Hatakkab K, Kinnunenb KT, Karjalainenb H, Saxelinb M, Laaksob K, Surakkab A, Palvac A, Salusjarvib T, Auvinena P, De Vos WM (2009) Comparative genomic analysis of Lactobacillus rhamnosus GG reveals pili containing a human mucus binding protein. Proc Natl Acad Sci 106: 17193-17198.

Kleerebezem M, Hols P, Bernard E, Rolain T, Zhou M, Siezen RJ, Bron PA (2010) The extracellular biology of the lactobacilli. FEMS Microbiol Rev 34: 199-230.

Kline KA, Falker S, Dahlberg S, Normark S, Henriques-Normark B (2009) Bacterial adhesins in host-microbe interactions. Cell Host \& Microbe 5: 580-592.

Lebeer S, Claes I, Tytgat HLP, Verhoeven TLA, Marien E, von Ossowski I, Reunanen J, Palva A, de Vos WM, De Keersmaecker SCJ, Vanderleyden J (2012) Functional analysis of Lactobacillus rhamnosus GG pili in relation to adhesion and immunomodulatory interactions witch intestinal epithelial cells. Appl Environ Microbiol 78: 185-193.

Pizarro-Cerda J, Cossart P (2006) Bacterial adhesion and entry into host cells. Cell 124: 715-727.

Reunanen J, von Ossowski I,. Hendrickx APA, Palva A, de Vos WM (2012) Characterization of the spaCBA pilus fibers in the probiotyic Lactobacillus rhamnosus GG. Appl Environ Microbiol 78: 2337-2344.

Roos S, Jonsson H (2002) A high-molecular-mass cell-surface protein from Lactobacillus reuteri 1063 adheres to mucus components. Microbiol-Sgm 148: 433-442.

Sambuy Y, De Angelis I, Ranaldi G, Scarino ML, Stammati A, Zucco F (2005) The Caco-2 cell line as a model of the intestinal barrier: influence of cell and culture-related factors on Caco- 2 cell functional characteristics. Cell Biol Toxicol 21: 1-26.

Sanchez B, Bressollier P, Urdaci MC (2008) Exported proteins in probiotic bacteria: adhesion to intestinal surfaces, host immunomodulation and molecular cross-talking with the host. FEMS Immunol Med Microbiol 54: 1-17.

Schmidt MT, Olejnik-Schmidt AK, Myszka K, Borkowska M, Grajek W (2010) Evaluation of quantitative PCR measurement of bacterial colonization of epithelial cells. Pol J Microbiol 59: 89-93.

Suau A, Bonnet R, Sutren M, Godon JJ, Gibson GR, Collins MD, Doré J (1999) Direct analysis of genes encoding 16S rRNA from complex communities reveals many novel molecular species within the human gut. Appl Environ Microbiol 11: 4799-807.

Sybesma W, Molenaar D, van IJcken W, Venema K, Kort R (2013) Genome instability in Lactobacillus rhamnosus GG. Appl Environ Microbiol 79: 2233-2239.

Toh H, Oshima K, Nakano A, Takahata M, Murakami M, Takaki T, Nishiyama H, Igimi S, Hattori M, Morita H. (2013) Genomic Adaptation of the Lactobacillus casei Group. PLoS One 8: 8-10.

Working Group on Drafting Guidelines for the Evaluation of Probiotics in Food, London, Ontario, Canada, April 30 and May 1. 2002. Available at: http://http://www.who.int/foodsafety/fs_management/en/probiotic_guidelines.pdf. Accessed 07 November 2013. 